\title{
Chapter 7 \\ Knowledge and Action for Change \\ Through Culture, Community \\ and Curriculum
}

\section{Linda Furuto}

\begin{abstract}
At the 1984 International Congress on Mathematical Education (ICME-5), Ubiratan D'Ambrosio envisioned the creation of a global society where "mathematics for all" reached an unprecedented dimension as a social endeavor by questioning the equilibrium of mathematics education $(1986$, p. 6). To respond to the challenge three decades later, I will present a contemporary perspective by re-examining the sociocultural role of mathematics education in the schooling process. I will specifically discuss how knowledge and action for change are achieved through intersections of culture, community and curriculum in an ongoing process of navigating and wayfinding in Hawai' $i$ and the Pacific. This will be accomplished by developing new theoretical insights into honoring and sustaining non-Western cultural systems and practices through examples in mathematics teacher education. In doing so, I will highlight diverse funds of teaching and learning that are grounded in a shared commitment to equity, empowerment and dignity.
\end{abstract}

Keywords Curriculum and instruction $\cdot$ Community $\cdot$ Culture-based education Equity

\section{1 "Mathematics for All"}

Three decades after the 1984 International Congress on Mathematical Education (ICME-5) where D'Ambrosio spoke about a vision of creating a society where "mathematics for all" reached an unprecedented dimension as a social endeavor (p. 6), we have come to understand that mathematics education is going through one of the most critical periods in its long recorded history since Western classical antiquity (Bishop 1988; Boaler 2002). The U.S. National Science and Technology Council's Federal Science, Technology, Engineering and Mathematics (STEM)

\footnotetext{
L. Furuto $(\square)$

University of Hawai'i at Mānoa, Honolulu, USA

e-mail: lfuruto@hawaii.edu

(C) The Author(s) 2018

G. Kaiser et al. (eds.), Invited Lectures from the 13th International Congress

on Mathematical Education, ICME-13 Monographs,

https://doi.org/10.1007/978-3-319-72170-5_7
} 
Education 5-Year Strategic Plan (2013) states, "We don't want our kids just to be consumers of the amazing things that science generates; we want them to be producers as well. And we want to make sure that those who historically have not participated in the sciences as robustly-girls, members of minority groups - are encouraged...this means teaching proper research methods and encouraging young people to challenge accepted knowledge" (p. 1). The current era emphasizes the role of an interconnected global society undergoing changing social, educational, political and economic conditions. Mathematics education has a direct role in influencing the equilibrium of achievement, particularly in traditionally underrepresented and underserved populations (Palhares and Shirley 2013; Weiss and Miller 2006).

To respond to the challenge of re-examining the sociocultural role of mathematics education in the schooling process, this article will discuss how knowledge and action for change are achieved through intersections of culture, community and curriculum in an ongoing process of navigating and wayfinding in Hawai' $i$ and the Pacific (Furuto 2016; Tuhiwai Smith 1999). The research goal is to develop new theoretical insights into honoring and sustaining non-Western cultural systems and practices through examples in mathematics teacher education that are grounded in a shared commitment to equity, empowerment and dignity (Rosa et al. 2016). The underlying premise is that "Mathematics is powerful enough to help us build a civilization with dignity for all, in which iniquity, arrogance, violence and bigotry have no place, and in which threatening life, in any form, is rejected. School ethnomathematics practices encourage the respect, solidarity and cooperation with others. It is thus associated with the pursuit of peace" (D'Ambrosio 2004, p. ix).

\subsubsection{Ethnomathematics and Ecological Systems Theory}

Defined as the intersection of historical traditions, sociocultural roots, political dimensions and linguistics, among others, ethnomathematics encourages the investigation and adaptation of these concepts within and outside of classrooms around the world (Greer et al. 2009; PREL 1995). The term ethnomathematics was introduced by D'Ambrosio in 1977 to foster an "awareness of the many ways of knowing and doing mathematics that relates to the values, ideas, notions, procedures and practices in contextualized environments" (Rosa et al. 2016, p. 1). By drawing on the assets and backgrounds of our students and communities, we acknowledge the importance of strengths-based approaches in accessing diverse funds of teaching and learning experiences (Hall 1993; Maton et al. 2003).

At the 2016 International Congress on Mathematical Education (ICME-13), Barton expanded on the ethnomathematics program and invoked the ecological systems theory. Ecological systems theory seeks to bridge the divide between science and the humanities in order to help students achieve responsible creativity and ethical citizenship (Bronfenbrenner 1979). In this system, “justice and education are part of a larger environment in which there is more than one 'way of 
knowing' resulting in a diversity of knowledge" (Barton 2017, p. 3). Barton continued, "The extent to which we free mathematics and mathematics education from society and culture is the extent to which we are absolving ourselves from responsibility to others and to our world. It frees us from social and cultural responsibility. Ultimately, this makes us amoral" (2017, p. 3). In other words, to do mathematics is to engage in processes of understanding and fulfilling our civic and moral responsibilities.

\subsection{Culture, Community and Curriculum}

\subsubsection{Theoretical Frameworks}

Over the past three decades, research has emerged to support equity and empowerment, especially in communities traditionally underrepresented and underserved in mathematics education. Some of the important theories that frame the discussion on curriculum and instruction include the following: culturally relevant pedagogy (Ladson-Billings 1995), culturally congruent pedagogy (Au and Kawakami 1994), culturally compatible pedagogy (Jacob and Jordan 1987), engaged pedagogy (Hooks 1994), everyday pedagogies (Nassir 2008), critical care praxis (Rolón-Dow 2005), and most recently, culturally sustaining pedagogy (Alim and Reyes 2011; Cammarota 2007; Irizarry 2007; Paris 2012; Winn 2011). According to Paris (2012), "The term culturally sustaining requires that our pedagogies be more than responsive of or relevant to the cultural experiences and practices of young people - it requires that they support young people in sustaining the cultural and linguistic competence of their communities while simultaneously offering access to dominant cultural competence" (p. 95).

Research is critical in the democratic struggle toward principles of social justice in our schools and society (Alim et al. 2011; Hill 2009; Kirkland 2011). The literature encourages pedagogical, curricular and teaching innovations in sustaining and extending the richness of the past in the current struggle to overcome deficit theories and strive toward strengths-based approaches in education (Chang and Lee 2012; Morrell 2004; Paris 2011). According to Rosa et al. (2016), the main foundation of an ethnomathematics program is embracing these types of diverse instructional practices and pedagogy that are integral as we move toward equity.

As an example of ethnomathematics, Math in a Cultural Context emerged from ethnographic work with Yup'ik elders and teachers (Lipka et al. 2005). The macro themes that evolved in this work concern positive changes in relationships, both in the classroom and between the classroom and community, pride in identity and culture, and ownership of knowledge. This curriculum is locally and culturally based while meeting both the State of Alaska's cultural standards and the standards of the National Council of Teachers of Mathematics (2000). Importantly, "this curriculum holds great promise to improve Alaska Natives students' mathematical 
understanding while bridging the culture of the schools to that of the community. It also can be viewed as a way to tap rich Indigenous cultural heritages, thus liberating from the legacy of colonial education and the restrictive pedagogical forms it prescribes" (Lipka et al. 2005, p. 368).

\subsubsection{Connections to Hawai ' $i$ and the Pacific}

Ethnomathematics has fundamental connections to Hawai'i and the Pacific. Research in Native Hawaiian communities demonstrates the importance of culturally sustaining pedagogy as a means of engaging and empowering students and their families in the learning process (Furuto 2014; Kana'iaupuni et al. 2010). According to Kana'iaupuni et al. (2017), "Embracing the emancipatory potential of culture-based education is a 'win' for everyone in our increasingly plurilingual, pluricultural society, who will benefit from the assets found in Indigenous knowledge, values, and stories as models of vitality and empowerment through which we can all progress" (p. 334). By drawing on Indigenous wisdom and 21st century knowledge, we have opportunities to re-examine the schooling process of Native Hawaiian and all students.

A tradition that has run deep in the Indigenous peoples of Hawai' $i$ and the Pacific for over 2000 years is open ocean, deep sea voyaging by celestial navigation without GPS systems, compasses, clocks or sextants (Baybayan et al. 1987; Finney et al. 1986; Goetzfridt 2008). Traditional wayfinding is done by the rising and setting of the sun, moon, stars, ocean swells, winds, currents, birds and principles of mathematics. Over time, knowledge of these traditional wayfinding techniques dwindled and nearly disappeared. However, in the past 40 years, traditional wayfinding has experienced a revival across the Pacific, especially in Hawai' $i$.

When the navigation renaissance began in the early 1970s by the Polynesian Voyaging Society (PVS), Native Hawaiians and others voyaged to prove that purposeful migration occurred across the Pacific (Goetzfridt 2008; Kyselka 1987; PVS 2016). Now, with the tradition of wayfinding revived and thriving, the voyages allow new generations of students to honor and sustain knowledge, culture and values through education. The Polynesian Voyaging Society's prototype canoe Hōkūle‘a ("star of gladness") has sailed over 150,000 nautical miles, and inspired a revival of voyaging and Indigenous practices around the world (Finney et al. 1986; Furuto 2014). With the guidance of master navigator Mau Piailug and PVS founders Herb Kāne, Ben Finney and Tommy Holmes, among others, Hōkūle'a has spawned a legacy of more than 25 deep sea voyaging canoes birthed across 11 Pacific Island nations.

Hōkūle'a's most recent voyage was to circumnavigate the globe from 2013 to 2017 with a mission to mālama honua, which is to "care for island earth" and all people and places as "ohana ("family"). It is a culture of caring for our students, schools, communities and homes. The author was on the first international leg from Hawai' $i$ to Tahiti as apprentice navigator and education specialist, and subsequent voyages to Samoa, Olohega (Swain's Island), Aotearoa (New Zealand), 
South Africa, Virginia, Washington, D.C. and New York City, sailing with leaders such as the Archbishop Desmond Mpilo Tutu, His Holiness the 14th Dalai Lama and United Nations (UN) Secretary General Ban Ki-moon. At the 2014 UN Small Island Developing States Conference in Samoa, Ban Ki-Moon presented PVS with a message in a bottle evocative of D'Ambrosio's challenge at ICME-5, "I am honored to be part of Hōkūle‘a's Mālama Honua Worldwide Voyage. I am inspired by its global mission. As you tour the globe, I will rally more leaders to our common cause of ushering in a more sustainable future and a life of dignity for all."

In this next section, I will highlight examples in mathematics teacher education through the lenses of ethnomathematics and voyaging that honor Indigenous wisdom and 21st century connections. Powell and Frankenstein (1997) urge, "As we more clearly understand the limits of our educational practice, we will increase the radical possibilities of our educational action for liberatory change. Thus, we feel the most important area for ethnomathematical research to pursue is the dialectics between knowledge and action for change" (p. 327). Through culture, community and curriculum, we have witnessed firsthand how this is possible.

\subsection{Knowledge and Action for Change}

Knowledge and action for enduring, transformational change comes from essential understandings gained by working with and learning from the populations we are endeavoring to serve. According to Jaworski et al. (1999), "Inservice providers cannot just 'deliver' a course, or a workshop, or a session. They must become part of the learning community, to live with the teachers and the learners and the realities of their situation. In doing so, inservice providers will necessarily influence and be influenced by that situation, and be an intimate part of any research the inservice providers might be engaged in as part of the development work" (p. 12). This is what we have strived to do as we have brought voyages back to land, especially in Hawai'i and the Pacific.

\subsubsection{Educational Context in Hawai ' $i$ and the Pacific}

Hawai' $i$ is the only statewide school district in the U.S., and operates a single public higher education University of Hawai'i System. As such, we have a unique opportunity to reach our schools through partnerships and strategic alignment. The long standing achievement gap of Native Hawaiian students in the Hawai'i State Department of Education and University of Hawai'i System represents a significant concern, and one that key stakeholders are committed to resolving (HIDOE 2017; UH IRO 2017). The connections from early childhood education through graduate studies (P-20) inspire meaningful, relevant and sustainable promising practices (Waitzer and Paul 2011; Weiss and Miller 2006). 
In Fall 2013, the Polynesian Voyaging Society's Promise to Children was authored by educational leadership in Hawai' $i$ and the Pacific, including the Hawai' $i$ State Department of Education (HIDOE) Superintendent and the University of Hawai'i System (UHS) President who participated as crew members on the Mālama Honua Worldwide Voyage. According to the Promise to Children, "We believe that the betterment of humanity is inherently possible, and we believe our schools, from early childhood education through advanced graduate studies, are a powerful force for good. This is the voyage of our lifetimes...the University of Hawai'i's 10 campuses have active programs and projects to achieve this goal such as...ethnomathematics learning" (p. 3). This alliance spans early childhood education through graduate studies (P-20), public and private sectors, and invites new partners to achieve collective impact (Bryk et al. 2011; Kania and Kramer 2011).

As a result of $\mathrm{P}-20$ collaborations, the HIDOE Office of Hawaiian Education created learning outcomes that all $\mathrm{K}-12$ students will achieve by graduation. Nā Hopena A'o (2015) is a product of the HIDOE's Mālama Honua Worldwide Voyage efforts to inform policy implementation at the statewide level. It is a framework to develop the skills, behaviors and dispositions of Hawai'i's unique context, and to honor the qualities and values of the Indigenous language and culture of Hawai'i. Nā Hopena A'o (HĀ) reflects the HIDOE's core values and beliefs in action throughout the public educational system of Hawai' $i$ to develop the competencies that strengthen a sense of belonging, responsibility, excellence, aloha, total well-being and Hawai' $i$ in ourselves, students and others (HIDOE 2015). With a foundation in Hawaiian values, language, culture and history, $\mathrm{H} \bar{A}$ supports a holistic learning process to guide the entire school community. The purpose of this policy is to provide a comprehensive outcomes framework to be used by those who are developing the academic achievement, character, physical and social-emotional well-being of students to the fullest potential (HIDOE 2015, 2017).

Similarly, the University of Hawai' $i$ System (UHS) is the sole provider of public higher education in Hawai' $i$, and is comprised of 10 campuses. It is committed to improving the social, economic and environmental well-being of current and future generations, and services the needs of students not just in Hawai' $i$ but throughout the Pacific, particularly in U.S. affiliated entities. Approximately $25 \%$ of the student population is Native Hawaiian (UH IRO 2017). The UHS Strategic Directions 2015-2021 guides the university's priorities to achieve systemwide outcomes, along with measurable goals and the ability to effectively monitor progress over time (UHS 2015). Interwoven in the strategic directions are two key imperatives embraced within the UHS mission - a commitment to being a foremost Indigenous-serving institution and advancing sustainability. With the Mālama Honua Worldwide Voyage as a catalyst, the UHS is firmly committed to advancing these directions in concert with its core values of academic rigor, excellence, integrity, service, aloha and respect (UHS 2015). According to the UHS, "There are powerful motivations for the University of Hawai'i to be supportive of its Indigenous population: some of its campuses sit on ceded lands; negative Native Hawaiian social and economic statistics exist; and inequity of success amongst its 
native and non-native students are factors that demand attention. There are many reasons...However, the best reason is because it is the right thing to do" (2012, p. 26).

\subsubsection{Preparing Teachers as Leaders}

The College of Education at the University of Hawai 'i's flagship Mānoa campus is the ideal vehicle to help achieve P-20 knowledge and action for change. The UH Mānoa College of Education directs online and in-person teacher preparation programs, professional development, curriculum development and research projects across Hawai' $i$ and U.S. affiliated Pacific Islands. It produces more than $65 \%$ of Hawai'i's teaching force and leads U.S. affiliated Pacific Islands in providing educational programs and professional development (UHM COE 2016). The underlying mission is to "envision a community of educators who provide innovative research, teaching and leadership in an effort to further the field of education and prepare professionals to contribute to a just, diverse and democratic society. The College aims to enhance the well-being of the Native Hawaiian people and others across the Pacific Basin through education" (UHM COE 2016, p. 2). The UH Mānoa College of Education is well-equipped to achieve UHS priorities, which include, "Continue improving P-20 education by establishing collaborative initiatives" (UHM COE 2016, p. 2).

The Ethnomathematics Institute is housed at the UH Mānoa College of Education, and the author is the principal investigator. Now in its 9th year, the project is an effort to address issues of equitable and quality education through culturally sustaining pedagogy grounded in the ethnic, cultural, historical, epistemological and linguistic diversities of Hawai'i and the Pacific. We bring together research institutions and community-based organizations to support yearlong professional development for P-20 inservice educators (note: for the first five years when the author was an Associate Professor of Mathematics at the University of Hawai' $\mathrm{i}$-West $\mathrm{O}$ 'ahu, the focus was on undergraduate students).

The three main objectives of the Ethnomathematics Institute are to: (1) explore promising practices in diverse, high needs populations in alignment with national and state standards, such as the Mathematics Common Core State Standards, Next Generation Science Standards and Nā Hopena A'o; (2) prepare teachers as leaders to provide instruction and professional development in ethnomathematics in their schools and communities through high-quality learning that is relevant, contextualized and sustainable; and (3) strengthen campus-community partnerships to build a research consortium within Hawai' $i$ and the Pacific. In addition to classroom learning, place- and culture-based learning occur throughout the Hawaiian islands.

For example, students and teachers sail on Polynesian Voyaging Society canoes to perpetuate the art and science of traditional voyaging and the spirit of exploration. Through experiential, hands-on curriculum development, they inspire their communities to respect and care for themselves, each other, and their natural and 
cultural environments. Some of the experiments performed on land and sea to link Indigenous wisdom and 21st century knowledge include: plankton tows and identification, water quality research, marine debris collection and identification, hydroponic food growing, marine mammal acoustics and fish DNA identification. These mathematics and science experiments were designed and implemented with support from the HIDOE and UH Mānoa School of Ocean and Earth Science and Technology, spanning the disciplines of oceanography, geology and geophysics, marine biology, agriculture and zoology.

The project is guided by the shared HIDOE and UHS values of belonging, responsibility, excellence, aloha, total well-being and Hawai'i. We honor our students by connecting the classroom to the local ecological, cultural, historical and political contexts in which schooling itself takes place. Following an ethnomathematics lesson implemented by one of the teacher leaders on Polynesian Voyaging Society canoes, a 12th grade student reflected, "Papahānaumoku/Haumea has given birth to our world. She helps to provide our food and materials needed to survive. So in return, we as the children must take care of the land by making sure our lifestyle is balanced and keeps Papahānaumoku hau'oli loa (very happy) by understanding related rates of change in the tides, caring for the canoes that teach us analytic geometry, and using the Cartesian coordinate system to cultivate native plants that crew members take on voyages" (H. Barbieto, personal communication, December 1, 2015).

Over the past nine years, the Ethnomathematics Institute has grown through successes, challenges and lessons learned. For the first five years at the University of Hawai' $\mathrm{i}$-West $\mathrm{O}^{\prime}$ ahu, performance measures included a $1400 \%$ increase in the number of students enrolled in mathematics courses as the general student body population grew from 940 students in 2007 to 2361 students in 2013 (UH IRO 2017). This led to the development of 11 new mathematics courses tied to institutional learning outcomes, accreditation and graduation requirements, all of which are grounded in ethnomathematics. Over the past four years, the Ethnomathematics Institute transitioned into a yearlong professional development program for $\mathrm{P}-20$ inservice educators, and has had participation of educators from all 15 complex areas and seven districts of the HIDOE. This has formed an integrated statewide network that demonstrates commitment to improving learner outcomes, particularly in traditionally underrepresented and underserved populations.

Next steps include institutionalizing the grant-funded Ethnomathematics Institute as a new academic program at the University of Hawai'i at Mānoa beginning in Fall 2018. As we work to become a stronger Indigenous-serving UHS, a new academic graduate-level program focused on preparing P-20 inservice educators to develop curriculum using both Western and non-Western approaches appeals to our diverse populations. The vision of preparing P-20 teachers as leaders to provide ethnomathematics instruction in their schools and communities strengthens the educational pipeline in alignment with the UHS Strategic Directions 2015-2021 and HIDOE Nā Hopena A'o. As stated by UHS President Lassner, "The new ethnomathematics graduate-level program will become a model for other 
programs interested in creating alternate pathways towards traditional academic goals" (D. Lassner, personal communication, April 27, 2017).

Research conducted by Bishop (1988) provides structure in the process of institutionalization. He asserts, "Of particular significance are the ideas that all cultural groups generate mathematical ideas, and that 'Western' mathematics may be only one mathematics among many...we must recognize the complex layers" (p. 179). We look forward to new developments guided by promising practices, and we know from quantitative and qualitative data that transformational change is occurring through the empowerment of individuals, schools, societies and nations. D'Ambrosio's declaration of a global society where "mathematics for all" reaches an unprecedented dimension as a social endeavor is not just a vision but a growing reality.

\subsection{Further Discussion}

Through developing new theoretical insights into honoring and sustaining non-Western cultural systems and practices, we have learned that we cannot change the winds but we can change our sails. When we change our sails, we often arrive not necessarily where we think we need to be, but exactly where we are supposed to be.

As a PVS apprentice navigator, I initially thought my responsibility was to arrive at a destination according to the sail plan. On the Mālama Honua Worldwide Voyage leg around the Samoan Islands, we planned to visit a number of islands but we were not able to due to the directional winds. Since it was necessary to return early to Pago Pago, American Samoa, we were able to interact with about 20 schools on Tutuila Island that were not in the original sail plan. Following our education presentation at Matatula Elementary School, the class expressed their appreciation and an 8-year old child stood and stated in the matai ("chief") language, "Thank you for teaching us what is not written in our textbooks" (I. Lagi, personal communication, September 30, 2015). The children remind us why we do the things we do, and they are the reason why we are voyaging the frontiers of education. Together we are writing the textbooks of island earth, and mathematics education is a powerful lens.

In conclusion, three decades after the 1984 International Congress on Mathematical Education (ICME-5), we have increasingly hopeful responses to the challenge of re-examining the equilibrium of mathematics education. Knowledge and action for change are continuing to be achieved through strengthening intersections of culture, community and curriculum in Indigenous wisdom and 21st century learning. In Hawai' $i$ and the Pacific, we explored these through navigating and wayfinding traditions, and the Ethnomathematics Institute being institutionalized as a new academic program at the University of Hawai'i at Mānoa.

As we reflect on our educational visions and calls to action, I am inspired by the 'ōlelo no"eau ("Hawaiian proverb") shared by International Commission on 
Mathematical Instruction (ICMI) President Ferdinando Arzarello to open the 2016 International Congress on Mathematical Education (ICME-13). "A A'ohe hana nui ke alu'ia-No task is too big when done together by all” (Pukui 1993, p. 18). Through storms and calm seas, we will change our sails as necessary and continue to remain steadfast in our firm commitment to equity, empowerment and dignity for all.

\section{References}

Alim, H., Ibrahim, A., \& Pennycook, A. (2011). Global linguistic flows: Hip hop cultures, youth identities, and the politics of language. London: Routledge.

Alim, H., \& Reyes, A. (2011). Complicating race: Articulating race across multiple social dimensions. Discourse \& Society, 22, 379-384.

$\mathrm{Au}, \mathrm{K} ., \quad \&$ Kawakami, A. (1994). Cultural congruence in instruction. In E. Hollins, J. King, \& W. Hayman (Eds.), Teaching diverse populations: Formulating knowledge base (pp. 5-23). Albany: SUNY Press.

Barton, B. (2017). Mathematics, education, and culture: A contemporary moral imperative. In G. Kaiser (Ed.), The Proceedings of the 13th International Congress on Mathematical Education (pp. 35-43). New York: Springer.

Baybayan, C., Finney, B., Kilonsky, B., \& Thompson, N. (1987). Voyage to Aotearoa. The Journal of the Polynesian Society, 96(2), 161-200.

Bishop, A. (1988). Mathematical enculturation: A cultural perspective on mathematics education. Ann Arbor: Kluwer Academic Publishers.

Boaler, J. (2002). Learning from teaching: Exploring the relationship between reform curriculum and equity. Journal for Research in Mathematics Education, 33(4), 239-258.

Bronfenbrenner, U. (1979). The ecology of human development. Cambridge: Harvard University Press.

Bryk, A., Gomez, L., \& Grunow, A. (2011). Getting ideas into action: Building networked improvement communities in education. http://archive.carnegiefoundation.org/pdfs/elibrary/ bryk-gomez_building-nics-education.pdf. Accessed April 24, 2017.

Cammarota, J. (2007). A social justice approach to achievement: Guiding Latina/o students toward educational attainment with a challenging, socially relevant curriculum. Equity and Excellence in Education, 40, 87-96.

Chang, B., \& Lee, J. (2012). “Community-based?” Asian American students, parents, and teachers in the shifting Chinatowns of New York and Los Angeles. AAPI Nexus, 12(2), 18-36.

D'Ambrosio, U. (1986). Socio-cultural bases for mathematical education. In M. Carss (Ed.), Proceedings of the 5th International Congress on Mathematical Education (pp. 1-6). New York: Springer.

D'Ambrosio, U. (2001). Ethnomathematics link between traditions and modernity. Rotterdam: Sense Publishers.

D'Ambrosio, U. (2004). Preface. In F. Favilli (Ed.), Ethnomathematics and mathematics education (pp. v-x). Pisa: Tipografia Editrice Pisana.

Finney, B., Kilonsky, B., Somseon, S., \& Stroup, E. (1986). Re-learning a vanishing art. Journal of the Polynesian Society, 95(1), 41-90.

Furuto, L. (2014). Pacific ethnomathematics: Pedagogy and practices in mathematics education. Teaching Mathematics and its Applications: International Journal of the IMA. https://doi.org/ 10.1093/teamat/hru009.

Furuto, L. (2016). Lessons learned: Strengths-based approaches to mathematics education in the Pacific. Journal of Mathematics and Culture, 10(2), 55-72. 
Goetzfridt, N. (2008). Pacific ethnomathematics a bibliographic study. Honolulu: University of Hawai'i Press.

Greer, B., Mukhodpadhyay, S., Powell, A., \& Nelson-Barber, S. (2009). Culturally responsive mathematics education. New York: Routledge Press.

Hall, S. (1993). Cultural identity and diaspora. In P. Williams \& L. Chrisman (Eds.), Colonial discourse and post-colonial theory: A reader. London: Harvester Wheatsheaf.

Hawai'i State Department of Education. (2015). Nä Hopena A' $o$. http://www.hawaiipublicschools. org/DOE\%20Forms/NaHopenaAoE3.pdf. Accessed April 24, 2017.

Hawai' $i$ State Department of Education. (2017). School data and reports. http://www. hawaiipublicschools.org/VisionForSuccess/SchoolDataAndReports/Pages/home.aspx. Accessed April 24, 2017.

Hill, M. (2009). Beats, rhymes and classroom life: Hip-hop pedagogy and the politics of identity. New York: Teachers College Press.

Hooks, B. (1994). Teaching to transgress. New York: Routledge.

Irizarry, J. (2007). Ethnic and urban intersections in the classroom: Latino students, hybrid identities, and culturally responsive pedagogy. Multicultural Perspectives, 9(3), 21-28.

Jacob, E., \& Jordan, C. (1987). Moving to dialogue. Anthropology and Education Quarterly, 18, 259-261.

Jaworski, B., Wood, T., \& Dawson, A. (1999). Mathematics teacher education: Critical international perspectives. New York: Routledge Press.

Kana'iaupuni, S., Ledward, B., \& Jensen, U. (2010). Culture-based education and its relationship to student outcomes. Honolulu: Kamehameha Schools, Research \& Evaluation.

Kana'iaupuni, S., Ledward, B., \& Malone, N. (2017). Mohala i ka wai: Cultural advantage as a framework for Indigenous culture-based education and student outcomes. American Educational Research Journal, 54(1), 311-339.

Kania, J., \& Kramer, M. (2011). Collective impact. http://www.ssir.org/articles/entry/collective_ impact. Accessed April 24, 2017.

Kirkland, D. (2011). Books like clothes: Engaging young Black men with reading. Journal of Adolescent \& Adult Literacy, 55, 199-208.

Kyselka, W. (1987). An ocean in mind. Honolulu: University of Hawai'i Press.

Ladson-Billings, G. (1995). Toward a theory of culturally relevant pedagogy. American Education Research Journal, 32, 465-491.

Lipka, J., Hogan, M., Webster, J., Yanez, E., Adams, B., Clark, S., \& Lacy, D. (2005). Math in a cultural context: Two case studies of a successful culturally based math project. Anthropology \& Education Quarterly, 36(4), 367-385.

Maton, K., Schellenbach, C., Leadbeater, B., \& Solarz, A. (2003). Investing in children, youth, families and communities: Strengths-based research and policy. Washington, DC: American Psychological Association.

Morrell, E. (2004). Becoming critical researchers: Literacy and empowerment for urban youth. New York: Peter Lang.

Nassir, N. (2008). Everyday pedagogy, lessons from basketball, track, and dominoes. Phi Delta Kappan, (March), 529-532.

National Council of Teachers of Mathematics. (2000). Principles and standards for school mathematics. Reston: National Council of Teachers of Mathematics.

National Science and Technology Council. (2013). Federal science, technology, engineering, and mathematics (STEM) education 5-year strategic plan. Washington, DC: Office of Science and Technology Policy Executive Office of the President.

Pacific Region Educational Laboratory. (1995). Pacific standards for excellence in teaching, assessment and professional development. Honolulu: Pacific Mathematics and Science Regional Consortium.

Palhares, P., \& Shirley, L. (2013). The role of ethnomathematics in mathematics education. Revista Latinoamericana de Etnomatemática, 6(3), 4-6.

Paris, D. (2011). Language across difference: Ethnicity, communication, and youth identities in changing urban schools. Cambridge: Cambridge University Press. 
Paris, D. (2012). Culturally-sustaining pedagogy: A needed change in stance, terminology, and practice. Educational Researcher, 41(3), 93-97.

Polynesian Voyaging Society. (2013). Promise to children. Honolulu: Polynesian Voyaging Society.

Polynesian Voyaging Society. (2016). The story of Hōküle'a. http://www.hokulea.com/voyages/ our-story/. Accessed April 24, 2017.

Powell, A., \& Frankenstein, M. (1997). Ethnomathematics: Challenging Eurocentrism in mathematics education. Albany: SUNY Press.

Pukui, M. K. (1993). 'Ōlelo no 'eau: Hawaiian proverbs and poetical sayings. Honolulu: Bishop Museum Press.

Rolón-Dow, C. (2005). Critical care: A color(full) analysis of care narratives in the schooling experiences of Puerto Rican girls. American Educational Research Journal, 42, 77-111.

Rosa, M., D’Ambrosio, U., Orey, D., Shirley, L., Alangui, W., Palhares, P., \& Gavarrete, M. (2016). ICME-13 topical surveys: Current and future perspectives in ethnomathematics. New York: Springer.

Tuhiwai Smith, L. (1999). Decolonizing methodologies: Research and Indigenous peoples. New York: Zed Books.

University of Hawai' $i$ Institutional Research Office. (2017). MAPS enrollment projections. http:// www.hawaii.edu/iro/maps_release.php. Accessed April 24, 2017.

University of Hawai' $i$ at Mānoa College of Education. (2016). Currents. Honolulu: University of Hawai'i at Mānoa College of Education.

University of Hawai'i System. (2012). Hawai' $i$ papa o ke ao. http://www.hawaii.edu/ hawaiipapaokeao/overview/. Accessed April 24, 2017.

University of Hawai'i System. (2015). University of Hawai $i$ strategic directions 2015-2021. http://blog.hawaii.edu/strategicdirections/files/2015/01/StrategicDirectionsFINAL-013015.pdf. Accessed April 24, 2017.

Waitzer, J., \& Paul, R. (2011). Scaling social impact, when everybody contributes, everybody wins. Innovations, 6(2), 143-155.

Weiss, I., \& Miller, B. (2006). Developing strategic leadership for district-wide improvement of mathematics education. Lakewood: National Council of Supervisors of Mathematics.

Winn, M. (2011). Girl time: Literacy, justice, and the school-to-prism pipeline. New York: Teachers College Press.

Open Access This chapter is licensed under the terms of the Creative Commons Attribution 4.0 International License (http://creativecommons.org/licenses/by/4.0/), which permits use, sharing, adaptation, distribution and reproduction in any medium or format, as long as you give appropriate credit to the original author(s) and the source, provide a link to the Creative Commons license and indicate if changes were made.

The images or other third party material in this chapter are included in the chapter's Creative Commons license, unless indicated otherwise in a credit line to the material. If material is not included in the chapter's Creative Commons license and your intended use is not permitted by statutory regulation or exceeds the permitted use, you will need to obtain permission directly from the copyright holder. 